Piotr OKNIŃSKI

Wydział Historyczny, Uniwersytet Warszawski

\title{
Uwagi do dyskusji nad najstarszą pieczęcią Krakowa z XIII w.
}

W niniejszym artykule chciałbym ustosunkować się do najważniejszych wątków dyskusji między Henrykiem Seroką, Błażejem Śliwińskim i Marcinem Starzyńskim w sprawie datowania oraz interpretacji najstarszej pieczęci miasta Krakowa ${ }^{1}$. Jej jedyny znany odcisk przywieszono na pergaminowym pasku do testamentu z 20 XII 1303 r., przechowywanego w archiwum franciszkańskim w Krakowie². $\mathrm{Na}$ początku XX w. zdjęcia testamentu i pieczęci opublikował Adam $\mathrm{Chmiel}^{3}$. Po dokonaniu autopsji dokumentu, w 2008 r. Dariusz Karczewski zauważył, że interesująca nas pieczęć zaginęła ${ }^{4}$, o czym przypomniał następnie Marcin Starzyński ${ }^{5}$. Muszę jednak zwrócić uwagę na niedostrzeżony do tej pory fakt, że pieczęci nie odnalazł przy wspomnianym dokumencie już Włodzimierz Budka ${ }^{6}$.

Na okrągłej, ukruszonej pieczęci o średnicy ok. $65 \mathrm{~mm}^{7}$ przedstawiono mur z kamiennych ciosów $\mathrm{z}$ bramą i trzema basztami o jednym oknie. Baszta środkowa przewyższa pozostałe. Widnieje nad nią tarcza z nieukoronowanym orłem. Między każdą basztą boczną a otokiem znajduje się nakryta koroną tarcza z godłem połuorzeł-połulew. Na baszcie prawej stoi św. Wacław, identyfikowany napisem, który biegnie w dół wzdłuż tarczy z orłem i środkowej baszty: S(anctus) WENCESLA(us). Na baszcie lewej stoi św. Stanisław, identyfikowany usytuowanym analogicznie do poprzedniego napisem: S(anctus) STANISLAV(s). W bramie klęczy lub stoi zakapturzona postać, zwrócona w geście modlitewnym ku św. Stanisławowi. W otoku fragment inskrypcji: [...]DVOCATI CI[...].

\footnotetext{
${ }^{1}$ H. Seroka, W sprawie początków pieczęci miejskiej Krakowa. Ze studiów nad średniowieczna sfragistyka miast małopolskich, w: Drogą historii. Studia ofiarowane profesorowi Józefowi Szymańskiemu w siedemdziesiąta rocznicę urodzin, red. P. Dymmel, K. Skupieński, B. Trelińska, Lublin 2001, s. 299-307; tenże, Herby miast małopolskich do końca XVIII wieku, Warszawa 2002, s. 22-30; B. Śliwiński, Nowa hipoteza o początkach godła Krakowa, „Annales Academiae Paedagogicae Cracoviensis", 21, Studia Historica, 3, 2004, s. 155-164; M. Starzyński, Uwagi w sprawie genezy najstarszej pieczęci Krakowa z XIII wieku. Na marginesie ostatnich badań, St. Źródł., 50, 2012, s. 25-40.

${ }^{2}$ Kraków, Archiwum Prowincji OO. Franciszkanów, G-I-2. Historię zainteresowań dokumentem zreferował drobiazgowo M. Starzyński, Uwagi w sprawie genezy, s. 25-28. Pierwszą edycję testamentu sporządził Franciszek Piekosiński, korzystając jednak wyłącznie z odpisu Wilhelma Gąsiorowskiego: KDm.K, cz. 3, wyd. F. Piekosiński, Kraków 1882, nr 368. Jedyną edycję opartą na autopsji oryginału, niestety pozbawioną aparatu krytycznego, przygotował D. Karczewski, Miejsce krakowskiego klasztoru franciszkanów w strukturze czesko-polskiej prowincji zakonnej, w: Mendykanci w średniowiecznym Krakowie, red. K. Ożóg, T. Gałuszka OP, A. Zajchowska, Kraków 2008, s. 95 n.

3 A. Chmiel, Pieczęć wójtowska krakowska z drugiej połowy XIII wieku, „Rocznik Krakowski”, 9, 1907, s. 213-223; autor podtrzymał ustalenia w kolejnych pracach, zestawionych przez M. Starzyńskiego, Uwagi w sprawie genezy, s. 29, przyp. 21. ${ }^{4}$ D. Karczewski, Miejsce krakowskiego klasztoru franciszkanów, s. 95 n.

${ }^{5}$ M. Starzyński, Uwagi w sprawie genezy, s. 25, przyp. 1. Badacz podjął próbę odnalezienia klisz ze zdjęciami dokumentu i pieczęci w archiwum Towarzystwa Miłośników Historii i Zabytków Krakowa, zakończyła się ona jednak niepowodzeniem, zob. tamże, s. 29, przyp. 21.

6 W. Budka, Barwy herbu miasta Krakowa, „Miesięcznik Heraldyczny”, 14, 1935, z. 1, s. 9, przyp. 1.

7 Według pomiarów wykonanych przez A. Chmiela, Pieczęć wójtowska, s. 215.
} 
$\mathrm{Na}$ aktualnym etapie dyskusji głównym przedmiotem rozważań jest datowanie wprowadzenia pieczęci do użytku kancelaryjnego. Począwszy od ustaleń Franciszka Piekosińskiego, jej powstanie datuje się na podstawie szczegółów ikonograficznych na okres rządów Leszka Czarnego ${ }^{8}$. Z tego właśnie okresu pochodzi pierwsza wzmianka o sigillum civitatis Cracowie w koroboracji dokumentu opata mogilskiego Engelberta z 25 IV 1283 r.9 Jak udowodnił A. Chmiel w polemice z F. Piekosińskim, pieczęć miejska wzmiankowana w koroboracji dyplomu z $1283 \mathrm{r}$. była prawdopodobnie tożsama z pieczęcią znaną z zaginionego obecnie odcisku przy testamencie z 1303 r., jednak z nieznanego powodu nie przywieszono jej do dokumentu z $1283 \mathrm{r} .{ }^{10}$ Wbrew nieuzasadnionej krytyce ze strony H. Seroki i B. Śliwińskiego, słuszności ustaleń A. Chmiela dowiódł ponad jakąkolwiek wątpliwość M. Starzyński $^{11}$. Ostatecznie jednak i on nie wykluczył możliwości posługiwania się przez miasto Kraków jakąś starszą, niezachowaną pieczęcią za rządów Bolesława Wstydliwego ${ }^{12}$.

Wydaje się, że głębszego namysłu wymaga, poruszona ostatnio marginalnie, kwestia identyfikacji nominalnego dysponenta omawianej tutaj pieczęci ${ }^{13}$. Zagadnienie to wiąże się z odczytem napisu otokowego. Pierwszą propozycję ustalenia jego brzmienia przedstawił F. Piekosiński, opierający się na analizie zdjęcia rysunku pieczęci autorstwa Kajetana Wincentego Kielisińskiego: + S - ADVOCATI CIVITATIS CRACOVIENSIS ${ }^{14}$. Inaczej rekonstruował napis A. Chmiel, który pracował na oryginalnym odcisku z 1303 r.: + S' ADVOCATI CIVITATIS ET CIVIVM CRACOVIENSIVM ${ }^{15}$. Rekonstrukcję wzorował na opisie pieczęci w koroboracji z 1303 r., gdzie nazwano ją własnością honorabilium virorum civium Cracoviensium. Inną koncepcję przedstawił Marian Gumowski: + S' ADVOCATI ET COMVNITATIS CIVITATIS CRACOVIE ${ }^{16}$. Ustosunkowując się do ostatniego pomysłu trzeba przypomnieć o nieuwzględnianej w bieżącej dyskusji informacji W. Budki o zaginięciu pieczęci. Nie można wykluczyć, że M. Gumowski obejrzał ją przed zaginięciem, jest jednak bardziej prawdopodobne, że zasugerował się brzmieniem legendy w otoku XIV-wiecznej pieczęci Krakowa. Tłok ten, zgodnie z ustaleniami A. Chmiela ${ }^{17}$, powstał w wyniku modyfikacji tłoka pieczęci z XIII w.: + S' CONSVLVM ET COMVNITATIS CIVITATIS CRACOVIE ${ }^{18}$. Najbardziej uzasadniony wydaje się więc odczyt proponowany przez A. Chmiela. Rekonstruowana w taki sposób legenda

\footnotetext{
${ }^{8}$ F. Piekosiński, Pieczęcie polskie wieków średnich, Kraków 1899, nr 252, s. 162.

${ }^{9}$ Kraków-Mogiła, Archiwum Opactwa OO. Cystersów, dok. perg. nr 34; Diplomata monasterii Clarae Tumbae prope Cracoviam, ed. E. Janota, Cracoviae 1865, nr 35, s. 28 n.

${ }^{10}$ F. Piekosiński, Pieczecie polskie, nr 185, s. 126; A. Chmiel, Pieczęć wójtowska, s. 220 n.

11 M. Starzyński, Uwagi w sprawie genezy, s. 29-35.

12 Tamże, s. 39, przyp. 95.

13 „Dysponent pieczęci to ,jednostka organizacyjna fizyczna lub prawna, osoba lub rodzina, której znak i (lub) nazwa utrwalone zostały na pieczęci”, Materiały do polskiego słownika sfragistycznego, oprac. A. Baniecki, D. Bednarek, D. Zygadło, R. Forysiak-Wójciński, P. Gut, J. Leśniewska, M. Hlebionek, „Archiwista Polski”, 59, 2010, z. 3, s. 46. Szerzej na ten temat w odniesieniu do pieczęci miejskich M. Adamczewski, Uwagi w sprawie systemów sfragistycznych $i$ typologii pieczęci miejskich, w: Dawne pieczęcie. Typologia - metody badań-interpretacje, red. Z. Piech, Kraków 2015, s. 99-144. ${ }^{14}$ F. Piekosiński, Pieczęcie polskie, nr 253, s. 161. Zdjęcie rysunku: Kraków, AP, Zbiór Fotograficzny, nr II/394. Drugi rysunek pieczęci tego autora zachował się w postaci oryginalnej: BKórn., AO III 252. P. Pokora, Rysunki pieczęci Kajetana Wincentego Kielisińskiego w zbiorach Biblioteki PAN w Kórniku, w: Zbiory pieczęci w Polsce, red. Z. Piech, W. Strzyżewski, Warszawa 2009, cz. I, nr 188, s. 422; Album rysunków pieczęci Kajetana Wincentego Kielisińskiego ze zbiorów Biblioteki Kórnickiej Polskiej Akademii Nauk, wyd. P. Pokora, Kórnik 2013, s. 140. Na różnice między rysunkami zwrócił uwagę M. Starzyński, Uwagi w sprawie genezy, s. 28, przyp. 18.

15 A. Chmiel, Pieczęć wójtowska, s. 222. Odczyt ten poddał nieuzasadnionym modyfikacjom M. Friedberg, Herb miasta Krakowa, „Rocznik Krakowski”, 28, 1937, s. 104.

${ }^{16}$ M. Gumowski, Najstarsze pieczęcie miast polskich XIII i XIV wieku, Toruń 1960, nr 211, s. 120 n. Odczyt ten jako możliwy do akceptacji przytoczył ostatnio M. Starzyński, Uwagi w sprawie genezy, s. 36.

17 A. Chmiel, Pieczęcie miasta Krakowa, Kazimierza, Kleparza i jurydyk krakowskich do końca XVIII wieku, „,Rocznik Krakowski”, 11, 1909, s. 92 n.

${ }_{18}$ Za przyjęciem takiej możliwości przemawiają niektóre cechy warsztatu M. Gumowskiego, zob. R. Forysiak-Wójciński, Sfragistyka miejska w Ossolineum - materiaty i zbiory po profesorze Marianie Gumowskim, w: Zbiory pieczęci w Polsce, s. 198 i materiały z sesji poświęconej temu uczonemu, w „Roczniku Polskiego Towarzystwa Heraldycznego”, 12 (23), 2013.
} 
mogła posłużyć za wzór inskrypcji na pieczęci Nowego Sącza, poświadczonej w użyciu w 1323 r.: $+\cdot \mathrm{S}($ igillum $) \cdot \mathrm{ADVOCATI} \cdot \mathrm{ATQUE} \cdot \mathrm{CIVIUM} \cdot \mathrm{D}(e) \cdot \mathrm{KEMNIZ}^{19}$.

Rozważając kwestię właściciela pieczęci Krakowa, A. Chmiel powołał się na jej opis w koroboracji testamentu z 1303 r. - [sigillum] honorabilium virorum civium Cracoviensium — oraz na podobieństwo jej ikonografii do późniejszej, XIV-wiecznej pieczęci miejskiej. Przesłanki te doprowadziły go do wniosku, że była to „pieczęć miejska krakowska, a nie osobista, więc nawet nie osobista pieczęć osoby piastującej godność czy urząd miejski" ${ }^{20}$. Wbrew temu spostrzeżeniu, W. Budka uznał, że „właścicielem pieczęci z 1303 r.” był wójt dziedziczny ${ }^{21}$. „Pieczęcią wójta” nazywał ją też Marian Friedberg22. M. Starzyński, powołując się na opinię M. Friedberga, uznał wójta za „dysponenta” pieczęci ${ }^{23}$. Jego zdaniem, pieczęci tej nie przywieszono do dokumentu opata mogilskiego z $1283 \mathrm{r}$. z powodu nieobecności wójta przy spisywaniu dyplomu, choć dopuścił także możliwość, że po wygotowaniu go w skryptorium klasztornym zamierzano go opieczętować w siedzibie władz miasta ${ }^{24}$.

Ustosunkowując się do przytoczonych wypowiedzi muszę zauważyć, że do tej pory nie poddano analizie wszystkich dokumentów, przy których zamierzano przywiesić tytułową pieczęć. Poza wspomnianymi już dyplomami z lat 1283 i 1303 można wskazać co najmniej trzy kolejne. Pierwszy z nich, wystawiony 27 III 1296 r. dla klasztoru cystersów w Welehradzie, zachowany jest $\mathrm{w}$ odpisie w kopiariuszu klasztornym ${ }^{25}$. Jako wystawców wymieniono kolejno wojewodów i kasztelanów krakowskich i sandomierskich oraz reprezentantów Krakowa: wójta Alberta, rajców i ławników. Dokumentem tym potwierdzono w imieniu Wacława II darowiznę Bolesława Wstydliwego na rzecz morawskiego klasztoru, a w koroboracji wspomniano tylko zbiorczo o pieczęciach wystawców. Następne dwa interesujące nas dyplomy zostały wystawione samodzielnie przez miasto i zachowały się w postaci oryginalnej, choć odciski krakowskiej pieczęci miejskiej nie dochowały się do czasów ich edycji:

- 11 I 1304 r.: dokument wójta Jaśka i sześciu rajców, zatwierdzający rozstrzygnięcie sporu między dziedzicami Woli i Chełmu a sołtysami Bronowic o użytkowanie wody z Rudawy ${ }^{26}$.

- 6 VIII 1306 r.: dokument wójta Alberta i trzech rajców, poświadczający sprzedaż 30 łanów przed bramą Sławkowską biskupowi Janowi Muskacie przez Mirosława Rożen²7.

\footnotetext{
${ }^{19}$ Kraków, AP, Zbiór luźnych pieczęci, nr 98. Pieczęć wisiała przy dokumencie władz Nowego Sącza z 21 I 1323 r.: tamże, dok. perg. nr 9; KDm.K, cz. 1, nr 13. Przy wspomnianym dokumencie widzieli ją Żegota Pauli i Kajetan Wincenty Kielisiński: Ż. Pauli, Starożytności galicyjskie, Lwów 1838, s. 43; F. Piekosiński Pieczęcie polskie, nr 239, s. 155 n.; P. Pokora, Rysunki pieczęci Kajetana Wincentego Kielisińskiego, cz. I, nr 188, s. 414; Album rysunków pieczęci, s. 133; zob. też M. Haisig, Studia nad legenda pieczęci miejskiej, Wrocław 1953, s. 95 n., 122; M. Gumowski, Herb i pieczęcie Nowego Sącza, „Rocznik Sądecki”, 4, 1960, s. 71-73; tenże, Najstarsze pieczęcie, s. 104 n.; I. Styczyńska, Historia herbów miasta Nowego Sacza, „Almanach Sądecki”, 8, 1999, nr 3, s. 3; W. Fabijański, Odlewy metalowe pieczęci w zbiorze sfragistycznym Zakładu Narodowego im. Ossolińskich we Wrocławiu (katalog), Wrocław 1999, nr 198, s. 69; H. Seroka, Herby miast małopolskich, s. 98. Dalsze, nieraz dyskusyjne, analogie dla napisów w otokach najstarszych pieczęci Krakowa i Nowego Sącza wymienia P. Dymmel, System sfragistyczny średniowiecznego Lublina. Próba rekonstrukcji w: Pieczęć w Polsce średniowiecznej i nowożytnej. Zbiór studiów, red. P. Dymmel, Lublin 1998, s. 196-200.

20 A. Chmiel, Pieczęć wójtowska, s. 216, 223; podobnie M. Gumowski, Najstarsze pieczęcie, nr 211, s. 120; B. Wyrozumska, Kancelaria miasta Krakowa w średniowieczu, Kraków 1995, s. 29.

${ }_{21}$ W. Budka, Barwy herbu, s. 10, przyp. 14.

${ }^{22}$ M. Friedberg, Herb miasta Krakowa, „Rocznik Krakowski”, 28, 1937, s. 103 n.; tenże, Kancelaria miasta Krakowa do połowy XVIII wieku, „Archeion”, 24-25, 1955, s. 282 n.

${ }^{23}$ M. Starzyński, Uwagi w sprawie genezy, s. 36.

24 Tamże, s. 37.

${ }^{25}$ KDMłp., t. 2, wyd. F. Piekosiński, Kraków 1876, nr 533.

${ }^{26}$ Kraków, Archiwum Bazyliki Mariackiej, dok. perg. nr 1; KDKK, cz. 2, wyd. F. Piekosiński, nr 242. Katalog Kościoła N.P. Maryi w Krakowie, wyd. E. Długopolski, „Teka Konserwatorów Galicyi Zachodniej”, t. 6, Kraków 1906, s. 55, nr II.

${ }^{27}$ Kraków, Archiwum Krakowskiej Kapituły Katedralnej, dok. perg. nr 83; KDKK, t. 1, nr 113; J. Laberschek, Krakowski zespół osadniczy w wiekach XIII-XVI. Rozwój terytorialny, „Rocznik Krakowski”, 71, 2005, s. 14 n.
} 
W koroboracjach wymienionych dokumentów wzmiankowano kolejno [sigillum] nostre Communitatis i [sigillum] civitatis Cracoviensis. Wszystkie formuły dyplomatyczne, które opisują krakowską pieczęć — z lat 1283, 1303, 1304 i 1306 — nazywają ją zatem własnością wspólnoty miejskiej. Możliwe nawet, że za sformułowaniem honorabilium virorum civium Cracoviensium w testamencie Sulisławy kryją się sami rajcy. Należy też podkreślić, że członkowie samorządu uczestniczyli w wystawianiu dokumentów z lat 1296, 1304 i 1306. Wydaje się zatem, że oprócz wójta dziedzicznego dysponentem pieczęci były władze samorządowe. Zwykle przyjmuje się, że znaczenie polityczne Krakowa i jego rady miejskiej wzrosło właśnie za rządów Leszka Czarnego i w okresie walk o panowanie w Małopolsce po jego śmierci ${ }^{28}$. Nie jest więc rzeczą przypadku, że miasto zaczęło wtedy używać własnej pieczęci, a następnie, w warunkach oddalenia władzy zwierzchniej za rządów Wacława II zwiększyło swój udział w dokumentowaniu czynności prawnych ${ }^{29}$. Hipoteza o posługiwaniu się przez władze krakowskie jakąś inną pieczęcią już za życia Bolesława Wstydliwego wydaje się więc trudna do akceptacji.

W świetle tych spostrzeżeń chciałbym ustosunkować się też do nowej interpretacji ikonografii pieczęci. Zazwyczaj przyjmowano, że przedstawiono na niej odcinek fortyfikacji miejskich ${ }^{30}$. Koncepcję tę zakwestionowali jednak H. Seroka i M. Starzyński, którzy utożsamiają obiekt architektoniczny z domem wójta Henryka u zbiegu ulic Brackiej i Gołębiej, uważanym przez część badaczy za pierwszą siedzibę władz miejskich Krakowa ${ }^{31}$. H. Seroka stwierdził, że budowla na pieczęci nie ma cech obronnych $^{32}$, mimo że wskazywał je w opisie pieczęci już A. Chmiel ${ }^{33}$. Z kolei M. Starzyński stwierdził, że na znanych mu polskich, czeskich i niemieckich zabytkach sfragistyki miejskiej mury wypełniają zwykle całą dostępną rytownikowi przestrzeń. Jak jednak słusznie zauważył, nie można wykluczyć, że twórca pieczęci Krakowa chciał przedstawić przede wszystkim bramę $e^{34}$. Fakt, że pieczęć wykonano przed budową murów miejskich nie może oczywiście przeczyć dotychczasowym interpretacjom jej przekazu symbolicznego ${ }^{35}$. Chciałbym też zauważyć, że podtrzymana przez obu autorów hipoteza identyfikująca oranta w bramie $\mathrm{z}$ wójtem nie została nigdy przekonująco udowodniona ${ }^{36}$.

Reasumując powyższe uwagi, sądzę, że należy wesprzeć przeprowadzoną przez M. Starzyńskiego weryfikację nowej hipotezy dotyczącej datowania pierwszej znanej pieczęci Krakowa. Nic nie stoi na przeszkodzie identyfikowaniu pieczęci znanej z zaginionego odcisku przy testamencie z $1303 \mathrm{r}$. z obiektem wzmiankowanym w koroboracji dokumentu Engelberta z 1283 r. Była to prawdopodobnie najstarsza pieczęć miasta, nie znajduję jednak żadnych dowodów na rzecz tezy, zgodnie z którą jej jedynym dysponentem był wójt dziedziczny. Nowa interpretacja jej ikonografii jest również pozbawiona podstaw źródłowych. Trudno zatem zgodzić się z opinią, że pieczęć ta „była przede wszystkim symbolem władzy i pozycji zajmowanej przez wójta dziedzicznego" ${ }^{37}$, choć napis w otoku akcentował

28 J. Wyrozumski, Kraków do schyłku wieków średnich, Kraków 1992, s. 187, 194 n.; M. Starzyński, Krakowska rada miejska, s. $172 \mathrm{n}$.

${ }^{29}$ K. Skupieński, Klasztory a początki dokumentu miejskiego w Polsce, w: Klasztor w mieście średniowiecznym i nowożytnym: materiaty z międzynarodowej konferencji naukowej zorganizowanej w Turawie w dniach 6-8 V 1999 r. przez Instytut Historii Uniwersytetu Opolskiego i Instytut Historyczny Uniwersytetu Wrocławskiego, red. M. Derwich, A. Pobóg-Lenartowicz, Wrocław-Opole 2000, zwłaszcza s. 101.

${ }^{30}$ Interpretację tę uzasadnił w toku analizy obszernego materiału porównawczego M. Haisig, Motywy średniowiecznej architektury $w$ sfragistyce miejskiej, w: Rozprawy $i$ materiaty z historii sztuki i kultury materialnej, red. K. Majewski, Wrocław 1948, s. 32.

${ }^{31}$ H. Seroka, Herby miast małopolskich, s. 26 n.; M. Starzyński, Uwagi w sprawie genezy, s. 38.

${ }^{32}$ H. Seroka, Herby miast małopolskich, s. 26.

33 A. Chmiel, Pieczęć wójtowska, s. 215 n.

${ }^{34}$ M. Starzyński, Uwagi w sprawie genezy, s. 38.

35 Por. H. Seroka, Herby miast małopolskich, s. 35; M. Starzyński, Uwagi w sprawie genezy, s. 38.

${ }^{36}$ H. Seroka, Herby miast małopolskich, s. 25; M. Starzyński, Uwagi w sprawie genezy, s. 38. Badacze przypisują autorstwo tej koncepcji M. Gumowskiemu, Najstarsze pieczęcie, nr 211, s. 120, podczas gdy wprowadził ją do literatury W. Budka, Barwy herbu miasta Krakowa, s. 10, przyp. 14; a następnie M. Friedberg, Herb miasta Krakowa, s. 104, przyp. 6.

37 M. Starzyński, Uwagi w sprawie genezy, s. 37. 
bez wątpienia jego zwierzchność nad miastem. Sądzę raczej, że stanowiła ona wspólną własność wójta i rady miejskiej, zaś wprowadzenie jej do użytku kancelaryjnego wynikało z umocnienia stanowiska politycznego Krakowa i jego samorządu za rządów Leszka Czarnego.

\section{Remarks about a Discussion on the Oldest Thirteenth-century Seal of Cracow}

The oldest seal of Cracow originating from the pre-1283 period, and known from a lost impression attached to a document from 1303, has recently become the topic of a lively discussion held by Henryk Seroka, Błażej Śliwiński and Marcin Starzyński, interested predominantly in dating the seal's introduction into chancery practice and interpreting its symbolics. The author of the article proposes new findings concerning the history of the impression from 1303 and subsequently polemicizes with a conviction shared by contemporary scholars, namely, that the first Cracow seal was at the exclusive disposal of the vogt. In his opinion the seal was the common property of the vogt and the town council, and its initiation was connected primarily with a reinforcement of the political status of the town and its self-government authorities at the time of Leszek the Black (1279-1288).

Kontakt do autora: p.okniński@student.uw.edu.pl 